\title{
Myoelectric silence following unopposed passive stretch in normal man
}

\author{
RONALD W ANGEL, STEPHEN G WAXMAN, AND JEFFERY D KOCSIS \\ From the Department of Neurology, Veterans Administration Medical Center and Stanford \\ University School of Medicine, Palo Alto, California
}

SUMMARY The response to unopposed passive muscle stretch applied during sustained contraction was studied in normal man. When the subject did not resist the stretching force, the initial response was a brief cessation of EMG activity in the elongated muscle. The myoelectric silence was observed repeatedly in muscles of the upper and lower limbs. The response to passive stretch is discussed in relation to the lengthening reaction and the inverse myotatic reflex. The silent period observed under these experiemental conditions is unlikely to be caused by Renshaw inhibition, a pause in spindle afferent discharge, or activity of the group II afferent reflex pathway. Possible mechanisms include autogenetic inhibition and a stretch-evoked decrease of fusimotor activity.

Among the reflexes used in clinical neurology, the best known is probably the tendon jerk, a muscular contraction elicited by brief mechanical stretch. This reflex is usually elicited with the muscle in its resting (non-contracted) state. In the work described here, we subjected normal muscles to sudden stretch during sustained voluntary contraction and observed the electromyographic response. The results are presented below and discussed in the light of known physiological principles.

\section{Material and methods}

Nine men and six women, aged 18-56 years, participated in the study. All were in good health and without known neurological disease. Tests were conducted with the pectoralis major in 14 subjects. To insure that the findings were not peculiar to that muscle, a number of others were tested: infraspinatus (three subjects), triceps brachii (two), thigh adductors (two), biceps brachii (one) and quadriceps (one).

Muscle action potentials were detected by means of Beckman silver/silver chloride electrodes coated with a conductive electrolyte and fastened to the skin by adhesive collars. The amplified action potentials were displayed on an oscilloscope, from which photographs were taken.

Address for reprint requests: Ronald $W$ Angel, Department of Neurolcgy, Veterans Administration Medical Center, 3801 Miranda Avenue, Palo Alto, California 94304 USA.

Accepted 26 March 1980
Tests of the pectoralis major were done with the subject seated and the right hand reaching directly forward to grasp the recording handle. Transducers on the handle produced voltages proportional to displacement and velocity of the subject's hand.

Forces were exerted on the recording handle by means of a coil spring and a DC torque motor. One end of the spring was fastened to the recording handle and the other to a stationary post, the spring extending horizontally to the subject's right. When the handle was in the correct starting position, the spring was under tension, exerting a force that tended to abduct the arm; to maintain this position, the subject had to exert a force of about five newtons by contraction of the adductor muscles, including pectoralis major.

The torque motor was coupled to the handle by means of a cable which ran parallel to the coil spring. When a switch was thrown by the examiner, the force on the cable increased stepwise from zero to about 25 newtons. Hence, the total force on the handle increased to about 30 newtons, pulling the arm laterally. The subject was instructed not to resist or make any other active response to the pull of the torque motor, but allow the arm to be abducted passively.

A storage oscilloscope was triggered by the switch that energised the torque motor or by voltage from the velocity transducer. Responses were identified and measured on the stored images or on photographs of the traces.

To study the response of the infraspinatus muscle, the relative positions of the subject and apparatus were reversed, so that the force of the spring pulled the arm toward the midline. Thus, the starting position was maintained by contraction of the abductor 
muscles, including the infraspinatus, and the pull of the torque motor caused passive adduction of the arm.

For tests involving the biceps and triceps, the shoulder was abducted to horizontal, the elbow was flexed to $90^{\circ}$, and hand reached forward to grasp the recording handle. Depending on the relative positions of the subject and apparatus, the correct starting position required active contraction of either the biceps or triceps, and the torque motor caused extension or flexion of the elbow.

To test the quadriceps femoris, the subject was seated on a table, under which the torque motor was placed. A nylon cord was looped around the ankle, coupling the leg to the coil spring, which extended posteriorly, tending to flex the knee. Maintenance of the starting position now required contraction of the thigh extensors, and the torque motor caused passive flexion of the knee. The beginning of the passive flexion was timed by means of an accelerometer taped to the ankle.

When different subjects and muscle groups were tested, the amounts of force exerted by the spring and torque motor were adjusted appropriately. Thus, a stronger spring was used with the quadriceps than with the triceps. In each case, the initial force of the spring was strong enough to require a steady "interference pattern" in the muscle being tested, and the force of the motor was strong enough to complete the passive movement in less than one-half second.

Special tests were conducted to determine the smallest amount of displacement necessary to elicit a silent period. During passive abduction of the arm, the lateral excursion of the hand was generally

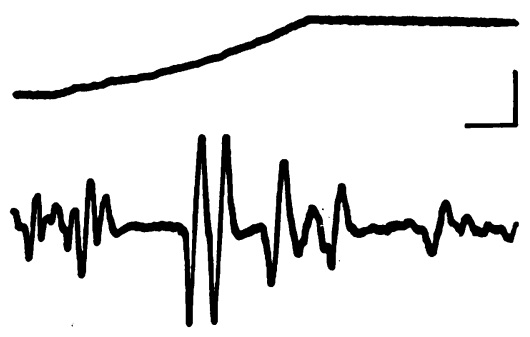

Fig 1 Myoelectric response to passive abduction of arm. Top: position of right hand. Abduction is shown by upward deflection. Bottom: surface EMG from right pectoralis major. As trace begins, the arm is extended directly forward and the pectoral muscle is contracted isometrically to prevent abduction of the arm by an external force. A sudden increase of the external force causes passive abduction, stretching the pectoral muscles. Subject was instructed not to resist the extra force. Within $70 \mathrm{~ms}$ after the start of the movement, the EMG shows electrical silence. Calibrations: EMG, $20 \mu \mathrm{V}$; time, $50 \mathrm{~ms}$, excursions of the top trace, $30 \mathrm{~cm}$. Calibrations are the same for all subsequent figures except where noted.
$20 \mathrm{~cm}$. On some trials, the movement was checked mechanically, limiting the excursion to various fractions of that distance. By this means, the hand movement could be limited to as little as $1 \mathrm{~cm}$, corresponding to less than $1.5^{\circ}$ of rotation at the shoulder joint.

\section{Results}

The typical response to unopposed passive stretch was a period of myoelectric silence. At the start of the trial shown in fig 1, the subject held his arm forward, resisting a laterally directed force by contraction of the pectoral muscles. The deflection of the upper trace indicates that the torque motor pulled the arm laterally, thereby lengthening the pectoral muscles. The subject had been instructed not to resist the sudden pull. Within $70 \mathrm{~ms}$ after the onset of the passive abduction, the EMG showed a period of silence lasting approximately $50 \mathrm{~ms}$. The phenomenon of the EMG silence following unopposed passive stretch was demonstrated readily and repeatedly in 22 of the 23 muscles tested, the one exception being in a pectoral muscle of one subject. The latency and duration of the silent period were often, but not always, similar on repeated trials (fig 2).

The silent period was elicited from the biceps by passive extension of the elbow. At the start of

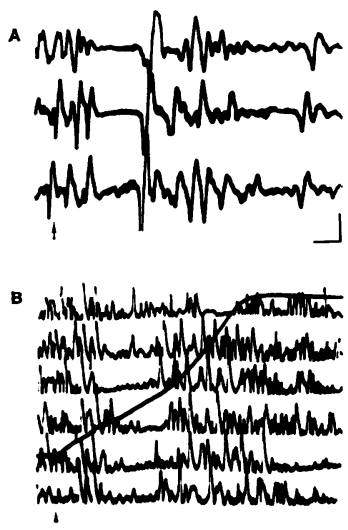

Fig 2 (A) Silent periods elicited by three passive abductions of right arm. On each trial, the lateral force is increased suddenly at the time shown by arrow. Complete electrical silence is seen in the top two traces and partial silence in the lowest one. (B) Myoelectric responses to six passive abductions of arm. The diagonal line shows movement of hand corresponding to top trace. On other trials, passive movement begins at the time shown by arrow. The rectified EMG traces indicate the variability of the silent period from trial to trial. 
each trial, the biceps was contracted against a force, and the subject was instructed not to resist the sudden pull of the torque motor. In response to the passive movement, the lengthened muscle (biceps) showed a reduction in electrical activity, but the shortened muscle (triceps) showed an increase in electrical activity, indicative of a shortening reaction.

For the responses shown above, the displacement of the hand was approximately $20 \mathrm{~cm}$, but passive displacements of much smaller magnitudes were also investigated. This was done in order to determine whether the period of myoelectric silence would terminate or continue after the cessation of passive stretch. By means of a mechanical block, the extent of hand movement during passive abduction of the arm was reduced successively from $20 \mathrm{~cm}$ to less than $1 \mathrm{~cm}$. Figure 3 shows a series of responses with graded amounts of stretch applied to the pectoralis major. From top to bottom, the amounts of hand movement shown are $20,8.6,3.2$ and $0.9 \mathrm{~cm}$. Despite the variation in the extent and duration of passive movement, a marked reduction of EMG activity is seen on each trace.

A silent period was also observed produced in the quadriceps femoris by stretch applied during contraction of that muscle. Two observations are illustrated in fig 4 . First, the silent period was not preceded by a burst of electrical activity which would be indicative of a muscle twitch. This makes it unlikely that the silent period was in response to a stretch-evoked contraction of the muscle. The second observation is that the

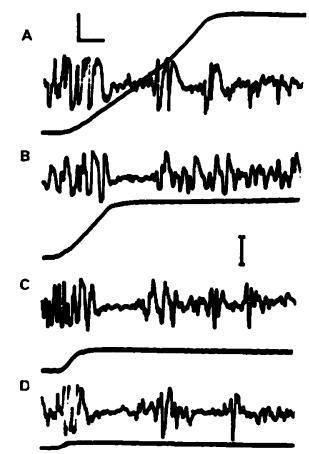

Fig 3 Responses of pectoralis to passive abductions of various extent. On the first trial (top) the hand is abducted $20 \mathrm{~cm}$ by the torque motor. On the other three trials, movement is checked mechanically after various amounts of movement. In the lowest trace, movement is arrested when the hand has been moved less than $1 \mathrm{~cm}$. A silent period occurs despite the limitation of movement. Calibration under trace $B$ : $5 \mathrm{~cm}$.
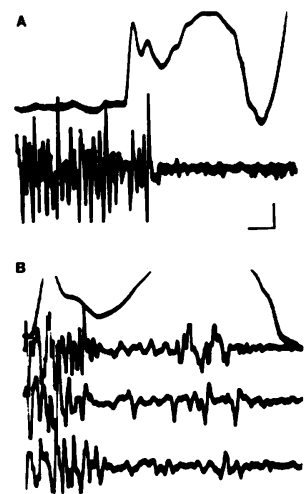

Fig 4 (A) Silent period evoked by passive stretch of quadriceps. Top: acceleration of leg. Bottom: EMG. As trace begins, subject holds the knee joint at $90^{\circ}$, resisting a backward force. At the time shown by deflection of top trace, the leg is pulled backward by torque motor, flexing knee and stretching quadriceps, which becomes electrically silent. Time calibration: $100 \mathrm{~ms}$. Acceleration: $0.2 \mathrm{~g}$. (B) Three repetitions of the same test. Top: acceleration of leg. Lower traces: quadriceps EMG showing silent periods.

Note that latencies are longer than those for muscles of upper limb. Time calibration: $50 \mathrm{~ms}$.

latency of the silent period in quadriceps was longer than the latencies found in the upper limb. For this subject, the mean latency of the silent period in quadriceps was found to be $130 \mathrm{~ms}(\mathrm{SD}=16)$. The latency of the silent period in the pectoralis major of the same subject was only $72 \mathrm{~ms}(\mathrm{SD}=10)$.

To help in excluding the possibility that the observed EMG responses were produced voluntarily, simultaneous records were made from the pectoralis major and the infraspinatus during both active and passive abduction of the arm. On "passive" trials, the subject was instructed to make no voluntary response to the pull of the motor. On "active" trials, he was instructed to abduct the motor as soon as possible when he detected the pull. Records made under these conditions showed two striking differences. On passive trials, the velocity curve rose more gradually to a relatively low peak (fig 5A). On active trials, the velocity curve showed an initial rise, caused by the motor, and then a much sharper rise, caused by the force of the abductor muscles (fig 5B). The resulting velocity was much greater than the maximum during passive trials. The interval between the first and second accelerations was well over $100 \mathrm{~ms}$, corresponding to published values for proprioceptive reaction times. ${ }^{1-3}$ 


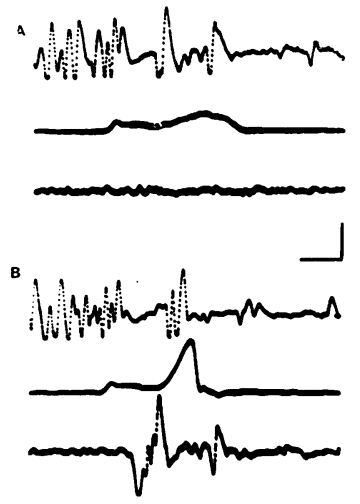

Fig 5 Comparison of active and passive movements. (A) Passive abduction of arm. Top: pectoral EMG. Middle: velocity of hand. Bottom infraspinatus EMG. As trace begins, pectoral muscle is contracted isometrically, resisting a lateral force which increases suddenly at the time shown by deflection of the velocity curve. Pectoral muscle becomes silent, and infrasp.natus shows no response to passive abduction. (B) Voluntary abduction. Initial conditions are the same, except that patient is instructed to abduct the arm voluntarily as soon as he perceives the pull of the motor. After the passive movement begins, the infraspinatus shows a burst of activity, followed by a sudden increase of hand velocity. Appearances of the velocity curve and infraspinatus EMG distinguish between passive and voluntary responses. Calibrations: time, $100 \mathrm{~ms}$, velocity, $100 \mathrm{~cm} / \mathrm{s}$.

A second difference was evident in the EMG records. On active trials the infraspinatus showed a sudden burst of activity, contrasting sharply with appearance on passive trials. The "twoburst" pattern shown in fig 5B is typical of voluntary ballistic movements. ${ }^{45}$

\section{Discussion}

The principal finding of this study was the decrease or interruption of EMG activity evoked by stretching a muscle during isometric, voluntary contraction. The phenomenon was observed on nearly every trial in which the subject did not resist the passive movement. It was readily demonstrated in all six of the muscle groups tested: adductors and abductors of the arm, flexors and extensors of the elbow, adductors of the thigh and an extensor of the leg. It was unobtainable in one pectoral muscle.

This phenomenon might be considered as an active inhibition of muscular activity at the motoneuronal level caused by passive stretch, but that description depends on two unproved assumptions: (1) that the silent period was elicited by an active inhibitory process, rather than some other mechanism such as disfacilitation of the motoneurons; and (2) that the response was mediated by stretch receptors. Lacking direct evidence for these assumptions, we have referred to the phenomenon by a purely descriptive name: "myoelectric silence following unopposed passive stretch."

This phenomenon can be viewed heuristically against the background of other responses known to be produced by stretching a muscle. Among these, the most familiar is undoubtedly the tendon jerk, which is a partial manifestation of the stretch reflex. ${ }^{6-7}$ However, the phenomenon that we observed appears diametrically opposite to the stretch reflex. Instead of contraction, we found a relaxation of the muscle, as shown by the electrical silent period.

A seeming precedent for this result was described by Hoffman, ${ }^{8}$ who recorded the EMG for a voluntarily contracted muscle during the tendon jerk reflex. As the muscle contracted, the EMG showed a brief cessation of activity. This silent period might seem analogous to the one found in our study, since both are elicited by stretching the muscle. However, the silent period following a tendon jerk can be explained by two mechanisms which do not apply to the results described here. When the tendon jerk is elicited, the spindle afferent impulses excite the motoneurons reflexly. The resulting twitch contraction shortens the muscle and thereby unloads the muscle spindles, which cease firing, as demonstrated by direct recording of single-unit activity in man. ${ }^{9}$ The silent period obtained by Hoffman can thus be explained as an unloading reflex, ${ }^{10}$ resulting from the sudden withdrawal of monosynaptic activation of spindle afferents. ${ }^{11}$ Another mechanism that could explain Hoffman's finding is Renshaw inhibition. The tendon jerk involves a highly synchronised burst of alpha motoneuron activity, which activates the Renshaw cells through recurrent collaterals, leading to inhibition of the motoneurons. Hence, the silent period following the tendon jerk could be explained in terms of spindle unloading, Renshaw inhibition, or both. In either case, the silent period following the tendon jerk represents a phenomenon distinctly different from the myoelectric silence elicited by a relatively slow passive stretch.

In the present study, the rate of muscle stretch was not generally fast enough to elicit a tendon jerk reflex, but on some trials there was an increase in the level of EMG activity preceding the silent period. However, this was quite different from the abrupt, synchronous volley 
that would indicate a tendon jerk reflex, and most of the observed silent periods were not preceded by any discernible increase of EMG activity. Hence, the silent period is not readily explained on the basis of spindle silence or Renshaw inhibition elicited by a twitch contraction.

Another form of stretch-evoked silent period was described by Hammond. ${ }^{12}$ In his experiments, the biceps was stretched during voluntary contraction, and the EMG showed a period of relative quiescence which Hammond attributed to inhibition via the Renshaw cells. Sears ${ }^{13}$ has noted that in one of Hammond's records there is clear evidence of inhibition following a light tap which extended the muscle but did not evoke a tendon jerk (reference 12, fig 3b). Although Hammond did not comment on this result, it seems quite analogous to the findings described here.

Experiments on the control of respiratory muscle provide another example of decreased EMG activity after loading. Newsom Davis and Sears $^{14}$ recorded the EMG of an intercostal muscle during respiration and studied the effects of brief alterations in load. When the load was increased suddenly during expiration, the EMG showed a striking decrease of activity, with a latency between 19 and $22 \mathrm{~ms}$. The results were interpreted as showing an active inhibition of muscular contraction, at the very time when an increase would be predicted by the servo-theory of motor control. ${ }^{15}$ The findings resemble those found in our laboratory: cessation of EMG potentials at a time when the stretch reflex might be expected to produce an increase of activity.

The earliest evidence for a mechanism opposing the stretch reflex may be found in the classical work by Sherrington. ${ }^{16} \mathrm{He}$ observed that, following decerebation, the knee joint assumed the fully extended position, the extensor muscles being hypertonic. When the experimenter flexed the knee forcibly, the tonic resistance melted away, and the leg remained flexed, with little or no tendency to resume the extended position. The tension developed in the extensor muscles was about the same as that originally developed at a shorter length. This was called the lengthening reaction. A similar effect was noted in the chronic spinal dog. On forced flexion of the knee, the initial reflex resistance gave way suddenly, permitting continued flexion without resistance. Sherrington considered this "clasp knife reaction" to be an integral part of the lengthening reaction. The same effect can also be observed in human patients with spastic limbs.

Burke, Gillies and Lance ${ }^{17}$ postulated that the clasp-knife phenomenon is mediated by activity in Group II afferent fibres from secondary spindle endings in the spastic muscle. The melting of the stretch reflex, which gives the reflex its clasp-knife character, was believed to result from activity in the Group II afferent reflex pathway, released from supraspinal inhibition by the lesion causing spasticity. While this explanation may apply to the clasp-knife reflex in spastic patients, it cannot explain the results described here, because (1) our subjects were not spastic, and (2) the occurrence of the silent period was not length-dependent. As shown in fig 4, the phenomenon occurred whether the hand was abducted $20 \mathrm{~cm}$ or as little as $1 \mathrm{~cm}$. In contrast, the reflex inhibition mediated by the Group II afferent fibres is clearly lengthdependent. ${ }^{17}$

Like the silent period in our study, the lengthening reaction is essentially a decrease of muscular activity in response to an increase of length. One mechanism that could account for koth of these effects is the inhibition mediated in response to muscle tension by the Golgi tendon organs. Using monosynaptic testing of motoneuronal excitability, Laporte and Lloyd ${ }^{18}$ demonstrated the appearance of inhibition when the strength of the stimulus was increased just above the minimum for group I activation. They suggested that the inhibition was due to stimulation of the afferents from the Golgi tendon organs. It is now well known that Ib volleys from a muscle mediate disynaptic inhibition of motoneurons innervating the same muscle and its synergists. ${ }^{19}$ Laporte and Lloyd coined the term "inverse myotatic reflex" to describe this effect, because it is directly opposed to the myotatic (stretch) reflex. ${ }^{20}$ Although Henneman ${ }^{21}$ has questioned the term, it does serve to point up the opposition between the length control and tension control systems.

Whatever term is used, the inhibition produced by loading of the Golgi tendon organs would appear to provide a plausible explanation for the lengthening reaction and the clasp-knife effect, as well as the silent period observed in our work. However, Matthews ${ }^{22}$ believes that it is "unduly simple to equate the clasp-knife effect with the disynaptically mediated Ib autogenetic inhibition." He points to the experiments of Eldred $e t a l^{23}$ in which the discharge of a spindle afferent was recorded during the elicitation of the clasp-knife response. During slow forcible extension of a decerebrate cat's ankle, impulses 
from the spindle at first became intermittent and then stopped altogether. At this point, the muscle ceased to contract, and the clasp-knife reaction was observed. The cessation of spindle discharge suggested that the fusimotor fibres must have been inhibited. Hence, the cessation of muscular contraction might be attributed, at least in part, to the withdrawal of spindle excitation caused by inhibition of the fusimotor neurons during forcible stretch of the muscle.

Rymer et $a l^{24}$ have also questioned the view that the clasp-knife reflex is caused by the central inhibitory effects of Golgi tendon organ discharge. Using the decerebrate cat with a dorsal hemisection of the lower thoracic cord, they showed that the clasp-knife reflex is autogenetic and depends on muscle length. Recordings from muscle afferent fibres showed that the EMG reduction was not mediated by a decrease in Ia afferent discharge and was not well correlated with spindle secondary or tendon organ discharge. These workers proposed that the claspknife reflex may be produced by the central inhibitory effects of other muscle afferents possessing classical flexor reflex actions, including groups III and IV and perhaps non-spindle group II afferents.

Experiments with the decerebrate cat and the spinal dog can only provide clues about the results that we obtained with intact human subjects. This point is emphasised by the crucial effect of the instructions given to the subject. When the subject was instructed not to resist the applied force, the EMG nearly always showed a silent period. When the subject was instructed to resist, no silent period was seen. The observations suggest the importance of supraspinal factors in negulating the segmental resfonse to a load disturbance. Such suprasegmental factors are also suggested by the difference in latency of the response between upper and lower limbs, which is consistent with a "long loop" reflex, as discussed below.

Since the EMG silence was a function of "preparatory set" one may question whether it was merely a voluntary response to stimulation by the passive movement. Although the subjects wene instructed not to respond actively, one might still question whether the myoelectric response was due to "unconscious co-operation." However, the short latency of the silent period (considerably less than $100 \mathrm{~ms}$ in the upper extremity) rules out the possibility that subjects were responding to visual or auditory cues, because typical reaction times to auditory and visual stimuli are 140 and $180 \mathrm{~ms}$, respectively. ${ }^{2}$
Nevertheless, the latencies found in our subjects cannot in themselves exclude the possibility that the subjects were responding voluntarily to proprioceptive stimuli. When the arm was abducted voluntarily in response to passive stretch, the latency of the silent period in pectoralis was no shorter than that of the voluntary EMG response in the infraspinatus (fig 5B).

The records obtained during active and passive movements provide more convincing evidence. During passive abduction of the arm, the velocity curve was relatively flat, and the infraspinatus remained inactive (fig 5A). During active movement, the velocity curve showed two distinct phases: an initial (passive) acceleration caused by the motor and a second (active) acceleration caused by voluntary contraction of the abductor muscles (fig 5B). As a result, much higher velocities were attained during active movements.

The difference between active and passive responses was also evident on the EMG records. Voluntary abduction of the arm was distinguished by a sharp burst of activity in the abductor muscles, not seen during passive movements. In fig 5B the infraspinatus muscle shows a two-burst pattern, typical of voluntary ballistic movements. ${ }^{45}$

Even if the silent period is not produced voluntarily, its latency may be compatible with a transcortical reflex, as postulated by Phillips ${ }^{25}$ and demonstrated in the primate experiments cf Evarts. ${ }^{26}$ The mean latency of the silent period was measured in both the upper and lower limbs of one subject and was found to be longer in the quadriceps $(130 \mathrm{~ms})$ than in pectoralis $(72 \mathrm{~ms})$. Comparing the functional stretch reflex with the tendon jerk in muscles in the upper and lower limbs, Marsden et al ${ }^{27}$ used the differences of latency to support the notion that the stretch reflex is mediated through a pathway involving the cerebral cortex. Our preliminary data must be confirmed in more subjects before one can speculate about a possible "long loop" mechanism to explain the observations presented here.

A question raised by our observations is whether the arrest of muscular contraction plays a role in normal motor activity. One possible function of such a response would be to protect the muscle against possible damage caused by sudden overloading. However, the forces applied in these experiments were far weaker than those required to damage the muscle or tendon. Furthermore, the silent period was easily abolished by the subject's intention to resist the 
applied force.

Sears ${ }^{13}$ has suggested that, during the performance of a practised movement against a predictatle load, autogenetic inhibitory reflexes are actually suppressed. "This could be achieved in the programming of a voluntary movement if a centrifugal control were exerted on the disynaptic pathway transmitting Group Ib inhibition of Group Ib inhibition to motoneurons." He suggests further that the presynaptic inhibition of Group Ib terminals by the corticospinal tract fibres ${ }^{28}$ may be responsible for such control. A mechanism of this kind would account for the abolition of the silent period by instructions given to the subject.

The clinical applications of our findings remain to be explored. Future studies involving fatients with pyramidal tract, extrapyramidal or cerebellar lesions might be expected to show qualitative or quantitative changes in the resfonse to loading and passive stretch. The possible applications to clinical assessment and to the study pathophysiology appear to deserve further investigation.

This work was supported by the Medical Research Service, Veterans Administration and by a grant from the Multiple Sclerosis Society.

\section{References}

1 Chernikoff R, Taylor FV. Reaction time to kinesthetic stimulation resulting from sudden arm displacement. J Exp Psychol (Gen) 1952; 43:1-8.

2 Woodworth RS, Schlosberg H. Experimental Psychology. New York: Henry Holt and Co, 1954: 16.

3 Higgins JR, Angel RW. Correction of tracking errors without sensory feedback. J Exp Psychol (Gen) 1970; 84:412-6.

4 Angel RW. Electromyography during voluntary movement: The two-burst pattern. Electroencephalogr Clin Neurophysiol 1974; 36:493-8.

5 Angel RW. Electromyographic patterns during ballistic movement of normal and spastic limbs. Brain Res 1975; 99:387-92.

6 Liddell EGT, Sherrington C. Reflexes in response to stretch (myotatic reflexes). Proc $R$ Soc Lond (Biol) 1924; 96:212-42.

7 Liddell EGT, Sherrington C. Further observations on myotatic reflexes. Proc $R$ Soc Lond (Biol) 1925; 97:276-83.

8 Hoffman P. Die physiologischen Eigenschaften der Eigenreflex. In: Asher $\mathrm{L}$, Spiro $\mathbf{K}$, eds. Ergebnisse der Physiologie und Experimental Pharmakologie. Munich: Verlag, 1934: 507.

9 Burg D, Szumski AJ, Struppler A, Velho F. Afferent and efferent activation of human muscle receptors involved in reflex and voluntary contraction. Exp Neurol 1973; 41:754-68.
10 Hansen K, Hoffmann P. Weitere Untersuchungen über die Bedeutung der Eigenreflexe für unsere Bewegungen. I. Anspannungs-und Entspannungsreflexe. Z Biolog 1922; 75:293-304.

11 Angel RW, Eppler W, Iannone A. Silent period produced by unloading of muscle during voluntary contraction. J Physiol (Lond) 1965; 180: 864-70.

12 Hammond PH. An experimental study of servo action in human muscular control. In: Procee!ings of the Third International Conference on Medical Electronics. London: Institute of Electrical Engineers, 1960: 190-9.

13 Sears TA. The dual proprioceptive reflex control of human intercostal muscles. In: Andersen P, Jansen J, eds. Excitatory Synaptic Mechanisms. Proceedings of the Fifth International Meeting of Neurobiologists. Oslo: Universitetsforlaget, 1970: 351-4.

14 Newsom Davis J, Sears TA. The proprioceptive reflex control of the intercostal muscles during their voluntary activation. J Physiol (Lond) 1970; 209:711-38.

15 Sears TA. Servo control of intercostal muscles. In: Desmedt JE, ed. New Developments in Electromyography and Clinical Neurophysiology. Volume 3. Basel: Karger. 1973: 404-17.

16 Sherrington CS. On plastic tonus and proprioceptive reflexes. $Q J$ Exp Physiol 1909; 2:109-56.

17 Burke D, Gillies JD, Lance JW. The quadriceps stretch reflex in human spasticity. J Neurol Neurosurg Psychiatry 1970; 33:216-23.

18 Laporte Y. Lloyd DPC. Nature and significance of the reflex connections established by large afferent fibres of muscular origin. Am J Physiol 1952; 169:609-21.

19 Davson H, Segal MB. Introduction to Physiology, Volume 4. London: Academic Press, 1978: 100-3.

20 Lloyd DPC. Spinal mechanisms involved in somatic activities. In: Field J, Magoun HW, Hall VE, eds. Handbook of Physiology, Section I. Neurophysiology, volume 2. Washington: American Physiological Society, 1960: 929-49.

21 Henneman E. Spinal reflexes and the control of movement. In: Mountcastle VB, ed. Medical Physiology, volume 2. St. Louis: Mosby, 1968: 1733-49.

22 Matthews PBC. Mammalian Muscle Receptors ant their Central Actions. Baltimore: Williams and Wilkins. 1972: 445-8.

23 Eldred E. Granit R, Merton PA. Supraspinal control of the muscle spindles and its significance. J Physiol (Lond) 1953; 122:498-523.

24 Rymer WZ, Houk JC, Crago PE. Mechanisms of the clasp-knife reflex studies in an animal model Exp Brain Res 1979; 37:93-113.

25 Phillips CG. Motor apparatus of the baboon's hand. Proc $R$ Soc Lont (Biol) 1969; 173:141-74.

26 Evarts EV. Motor cortex reflexes associated with learned movement. Science 1973; 179:501-3.

27 Marsden CD, Merton PA, Morton HB. Latency measurements compatible with a cortical pathway 
for the stretch reflex in man. J Physiol (Lond) 1973; 230:58P-59P.

28 Andersen P, Eccles JC, Sears TA. Cortically evoked depolarisation of primary afferent fibres in the spinal cord. J Physiol (Lond) 1964; 27: 63-77. 